\title{
INNOVATION IN INDUSTRY AND ACADEMIA
}

\author{
A panel that explores innovation in two key areas with invited \\ speakers from industry and academia
}

\author{
Esther Baldwin \\ Intel Coprporation
}

\begin{abstract}
This Panel will feature invited speakers from industry and academia that will discuss how academia has fostered innovation through research partnerships and incubation centres that have resulted in new businesses, products and other "end values". The panel will explore the techniques used to foster and extract value from innovations in the two environments and discuss the challenges faced by industry and academy in this area. Industry research and development consortiums and internal innovation management practices that help fuel growth will be discussed followed by an open discussion with the audience. How each of these two segments had lead innovation practices, their successes and failures will be discussed.

There are three types of innovation that will be used by the panel to evaluate industry and academia. Radical innovation - the invention of a completely new concept or product that radically affects a key aspect of business or life as we know it. Incremental innovation - the improvement of an existing process, product or technology in order increase its value or differentiate it in the marketplace. Re-applied Innovation - cognitive transfer that allows a product or process to be re-applied in a new application area.

Several problems will be discussed by the panel and the audience will be asked to participate in identifying new solutions.

Innovation in Industry: Industries have grown from the radical innovations of one or two people. The innovators that developed the "firsts" spend considerable time and usually capital in seeing their invention become reality. Seldom have the initial inventors been the people that benefited most financially from the consumption and mass production of a radical innovation. Is this a problem and is anyone working in this area?

Re-applied innovation is seldom seen in industry and usually is part of the diffusion of innovation process that results in people from diverse disciplines making the cognitive transfer that takes innovations to a new field or application. Re-applied innovation is most seen in industry when duress is placed on a company due to major radical or incremental innovations (by
\end{abstract}


someone else) and is used to help them survive these inflection points that may have eliminated their primary customer base. This is a reactive approach. If you consider that re-applied innovation is the area of least activity in both industry and academia and usually results in additional returns on already sunk capital and people investment. It is the area for highest potential to fuel growth. What can be done to increase success in this area will be explored.

The panel members will discuss innovation and how it is managed in industry by companies such as Intel ${ }^{\circledR}$ Corporation. Charles House (Director of Societal Impact of Technology) will represent innovation in industry. His current research is on Advanced Productivity Initiatives for Intel's IT group. House was recently named to the Electronic Design Hall of Fame to join others such as Hewlett, Packard, Noyce, Moore, Grove, and Hoff from HP and Intel - also Edison, Marconi, Tesla, Edwin Armstrong, \&, surprise, Hedy Lamarr.

Also discussed will be innovation in National Research Facilities: Government funded research in an academic and quasi-industrial environment to promote topics of interest to their respective governments and communities. Research and innovations from these environments frequently flow into industry and commercial products result, many from re-applied innovation e.g. ceramic tile technology used on the space shuttle is used in high heat commercial applications. How good are we at extracting value from innovations at these facilities?

Academia has excelled in the incubation and research of innovative ideas and in recognizing that there is more value in innovation than an end product. There are many examples of Research consortiums and incubation facilities in academia that encourage the development of innovations and even the translation of innovations into viable businesses. Academia does a much more thorough job of protecting these ideas with patents and promoting their ideas through publication. The President of the National College of Ireland Dr Joyce O'Connor will be one the panelists representing Academia.

Academia is the source of much potential radical innovation today and it is often funded by grants from industry. The partnership that has evolved between industry and academia is leading to innovations reaching the marketplace and financial remuneration for both parties involved. Converting intellectual capital into economic capital is a challenge for both industry and academia and often innovations have languished in the prototype stage without being driven to further end value. Academia has led the two groups in forming incubation centres and partnering with small innovators in order to convert idea into commercial products. Industry is just starting to manage innovation to multiple end values other than products. Intel's Network of University Labs represents a new form of industry-university collaboration that will be explored. How can we as an Innovation community reinforce each other and leverage our strengths?

Key words: Radical Innovation, Incremental Innovation, Re-applied innovation, end value, incubation, diffusion, collaboration, Innovation Management; Fostering a culture of Innovation; Innovation Partnerships and Consortia; 